\title{
Evaluation of a Tensile Test for Direct Filling Resins
}

\author{
G. T. EDEN,* R. G. CRAIG, and F. A. PEYTON \\ University of Michigan, School of Dentistry, Ann Arbor, Michigan 48104
}

Dental filling resins bond to enamel and dentin with varying ability. Quantitative determination of the strength of these resintooth bonds has been reported after shear loading, ${ }^{1-3}$ tensile loading, ${ }^{4,5}$ and complex loading. ${ }^{6,7}$

The shear tests require relatively simple equipment for specimen preparation, conditioning, and testing, and offer a relatively high degree of reliability. The test methods, using complex loading, do not permit the determination of either the tensile strength or the shear strength of the adhesive bond because of specimen geometry, although the clinical situation is closely approximated in that adhesive fillings are actually pulled from human teeth.

The tests described by Swartz and Phillips ${ }^{4}$ and Bowen ${ }^{5}$ measure the tensile strength of the adhesive bond, which is probably the governing parameter in clinical adhesion. Neither test, however, controls the thickness of the adhesive resin, which is shown here to affect bond strength. In addition, Bowen's test requires complicated machined subassemblies whose cost limits the sample size; Swartz and Phillips ${ }^{4}$ test requires large sample sizes because of poorer test sensitivity.

The subcommittee on testing methods for direct filling resins of the IADR had proposed a test method ${ }^{8}$ intended to eliminate the disadvantages inherent in these tensile tests.

The purpose of this research was to eval-

Based on a thesis submitted in partial fulfillment of the requirements for the MS degree at the University of Michigan, 1969.

This investigation was presented at the 47th Annual Meeting of the IADR, Houston, Texas, March 21, 1969.

The opinions expressed herein are those of the authors and cannot be construed as reflecting the views of the Navy Department or the Naval Service at large. The use of commercially available products does not imply endorsement of these products or preference to other similar products on the market.

Received for publication May 16, 1964.

* Present address: USS Howard W. Gilmore (AS16), FPO NY/NY 09501. uate this proposed test method, and modify it as necessary so that it would be capable of ranking the bonding abilities of currently available filling resins to hard dental substrates.

\section{Materials and Methods}

Substrates. - Aluminum disks were used to establish the reliability ${ }^{9}$ of the test method. The uniformly high bond strengths developed between dental resins and high energy metal surfaces may not relate to the dental problem; but the highly reproducible metal surfaces allowed an evaluation of test reliability without the relatively greater contributions to test variance expected from inherently more variable biologic substrates, such as enamel or dentin.

Fluorapatite-resin bond strengths were measured to evaluate bonding to the inorganic portion of the tooth.

Bovine enamel and dentin, which preserve the rank order of bonding abilities of dental resins tested against human enamel and den$\mathrm{tin}^{2}$ were used to approximate "in vivo" bonding. Using bovine teeth, the ability of the test to discriminate among the bonding abilities of various filling resins was shown by bond strength data.

Substrate mounting.-Bovine incisors, extracted from freshly killed animals, were mounted as shown in Figure 1. The flat spot on the labial surface was prepared by wet grinding with 180 -grit $\mathrm{SiC}$ paper. For dentin specimens, wet grinding with 80 grit $\mathrm{SiC}$ paper exposed sufficient dentin for further surface preparation. Steel mounting rings with one inch inside diameter were used throughout, and specimen thickness was determined by the amount of material necessary to completely cover the crown. After curing, the mounted teeth were refrigerated in tap water until used.

Flourapatite single crystals about one-half inch in diameter were similarly mounted exposing the 100 plane. 


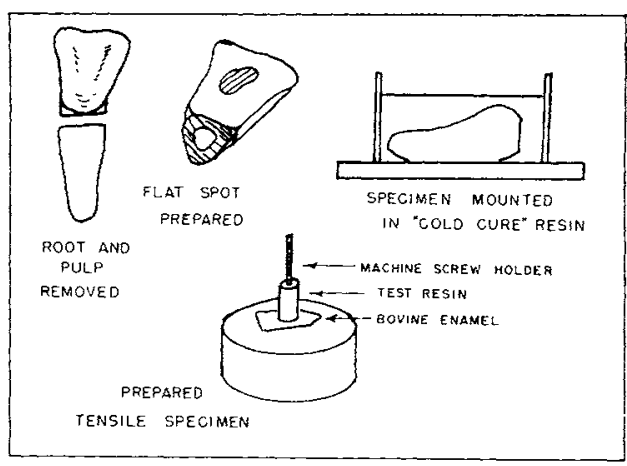

FIG 1.--Specimen preparation.

Aluminum disks cut to one-fourth inch thickness from one-inch rods were used, as cut, for further surface preparation.

SURFACE PREPARATION.-Surface preparation of enamel, dentin, fluorapatite, and aluminum consisted of wet grinding with 240,320 , and 400 grit $\mathrm{SiC}$ papers. The surface was then rinsed with distilled water and the frank water was blown from the surface with a bulb air-syringe.

The orientation of the fluorapatite crystals during mounting ensured that larger areas of the 100 plane of the crystal were exposed during surfacing.

Surface treatment.-Because adhesion to dentin is enhanced by a citric acid etch, ${ }^{2}$ $0.2 \mathrm{~N}$ citric acid ( $\mathrm{pH} 2.3$ ) was applied to some enamel and dentin surfaces for 20 minutes immediately before specimen preparation.

Then 2.0 molar $\mathrm{MgCl}_{2}$ was applied to some enamel and dentin surfaces in the same manner as the citric acid. The object of this treatment was the chemical removal of enamel keratin or collagen smeared over the tooth surface during the wet grinding procedure. ${ }^{10}$ The $\mathrm{MgCl}_{2}$ treatment was followed by a distilled water rinse and removal of frank water with a bulb air-syringe.

SPECIMEN DiE.-Teflon disks, one inch in diameter and three-tenths inch thick, with a $5 \mathrm{~mm}$ diameter hole centrally drilled, were used as dies to limit the spread of the test resins on the substrate surfaces. The permeability of Teflon to oxygen caused a thin layer of poorly polymerized material on the surface of the specimen contacting the die for some resins. The effect of this layer on bond strength was evaluated by purging the die of oxygen and replacing it with nitrogen.
Bond strengths were not significantly affected by the thin layer of poorly polymerized material $\left(t^{\circ}{ }_{.05(20)}=2.09>t_{(20)}=1.29\right.$, not significant).

SPECIMEN HOLDER.-Machine screws (size 2 to 56) were selected as holders, which permitted the specimens to be gripped by the testing instrument without misalignment of the specimen relative to the testing jig and without preloading of the adhesive interface while clamping into the grip of the testing instrument* (Fig 2,3).

The following holders were evaluated, but rejected because they contributed to lower mean bond strengths or increased variance: aluminum nails, straight pins, notched orthodontic wires, and larger machine screws.

SPECIMEN PREPARATION.-A simple jig was constructed to position the mounted substrate, Teflon die, and holder for casting the resin against the substrate surface (Fig 2 ). The movable stage, controlled by wing nuts, allowed compensation for slight lack of parallelism of the ends of the cylindrically mounted specimen. The holder was gripped in the jaws of a precision chuck mounted on a penetrometer $\uparrow$ equipped with a dial gauge. After noting the dial gauge

* Instron TT-BM, Instron Corporation, Canton, Mass.

+ Micrometer Adjustment Penetrometer, Krebs Elec. \& Mfg. Co., New York, NY.

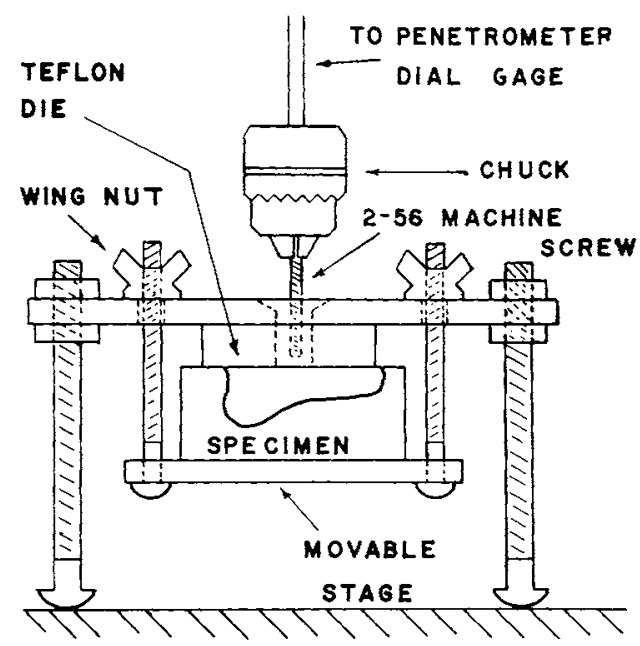

PENETROMETER BASE

FIG 2.-Specimen preparation jig. 


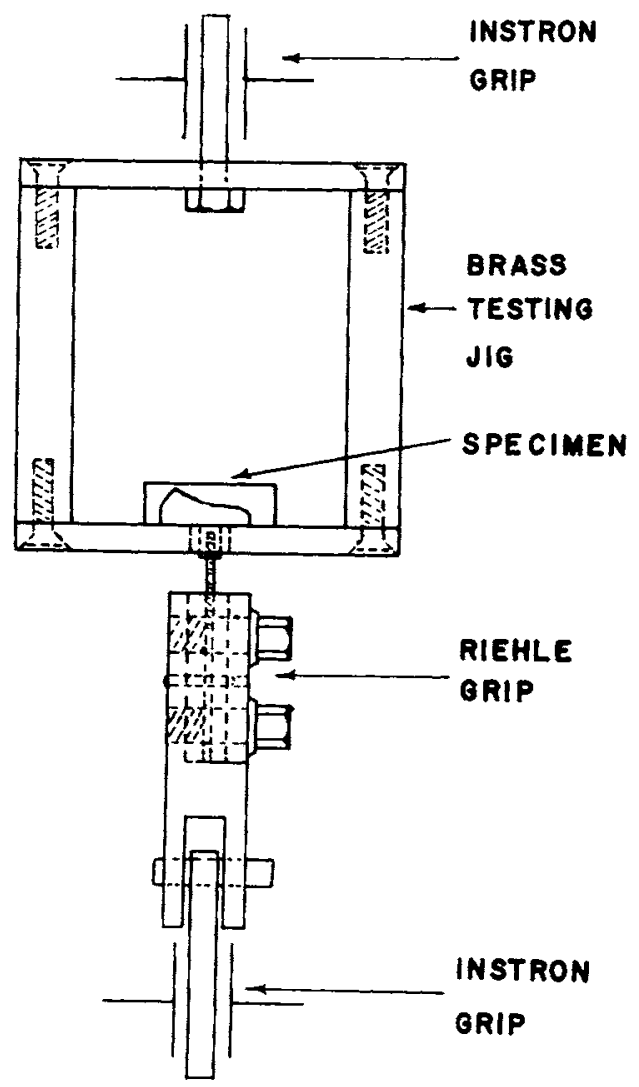

Fig 3.--Specimen testing jig. position when the holder was placed $1 \mathrm{~mm}$ above the substrate surface, the holder was retracted from the die cavity and placed at the indicated gauge position after insertion of the freshly mixed resin. The reproducible placement of the machine screw holder eliminated resin thickness as an important test variable. When bond strengths were determined for the resin 4-aluminum substrate combination, at resin thicknesses of 1 and $2 \mathrm{~mm}$, the difference in mean bond strengths was significant at the .05 level $\left[t^{\circ}{ }_{.05(16)}=\right.$ $\left.2.12<t_{(16)}=3.11(p<.01)\right]$

The five commercially available dental resins used during test development and evaluation are listed in Table 1. Resins 1, 2,3 , and 4 were purchased locally, whereas resin 5 was a manufacturer's sample.

Cavity primers were applied to the substrate surface when supplied in the manufacturer's kits. Cavity liners whose function was to protect the pulp were not used. Test resins were mixed and placed in the die cavity according to manufacturer's directions and the resin, exposed at the open end of the die cavity, was protected with watersoluble wax during polymerization.

Specimens spent 20 minutes in the preparation jig and 20 minutes at ambient temperatures on the bench before unmolding and conditioning in mouth-temperature tap water for 24 hours. The scope of this in-

TABLE 1

TEST RESINS

\begin{tabular}{|c|c|c|c|c|}
\hline Resin & Brand Name & Type & & tch No. \\
\hline 1 & $\begin{array}{l}\text { Bonfil } \\
\text { (L.D. Caulk Co. } \\
\text { Milford, Del) }\end{array}$ & $\begin{array}{l}\text { Unfilled } \\
\text { acrylic }\end{array}$ & $\begin{array}{l}27750 \\
26952 \\
33252\end{array}$ & $\begin{array}{l}\text { Powder } \\
\text { Liquid } \\
\text { Primer }\end{array}$ \\
\hline 2 & $\begin{array}{l}\text { Sevriton } \\
\text { (Amalgamated Dental } \\
\text { Trade Distributors, } \\
\text { Ltd., London, Eng) }\end{array}$ & $\begin{array}{l}\text { Unfilled } \\
\text { acrylic }\end{array}$ & 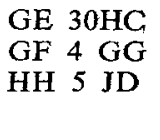 & $\begin{array}{l}\text { Powder } \\
\text { Liquid } \\
\text { Cavity Seal }\end{array}$ \\
\hline 3 & $\begin{array}{l}\text { Dakor } \\
\text { (L.D. Caulk Co. } \\
\text { Milford, Del) }\end{array}$ & Composite & $\begin{array}{r}11353 \\
8653 \\
9653 \\
8753 \\
4353 \\
353\end{array}$ & $\begin{array}{l}\text { Batch numbers of } \\
\text { various colors in } \\
\text { each clinical kit } \\
\text { Catalyst No. } 1 \\
\text { Catalyst No. } 2\end{array}$ \\
\hline 4 & $\begin{array}{l}\text { Addent } 35 \\
\text { (Minnesota Mining and } \\
\text { Manufacturing Co. } \\
\text { St. Paul, Minn) }\end{array}$ & Composite & 8099-02 & \\
\hline 5 & $\begin{array}{l}\text { Durelon } \\
\text { (ESPE Fabric Pharmazeu- } \\
\text { tischer Praparate GMBH) }\end{array}$ & $\begin{array}{l}\text { Composite } \\
\text { Carboxylate } \\
\text { Cement }\end{array}$ & $\begin{array}{l}047 \\
035\end{array}$ & $\begin{array}{l}\text { Powder } \\
\text { Liquid }\end{array}$ \\
\hline
\end{tabular}


vestigation was limited to the development of a test method, and the short conditioning time used does not affect the utility of the test. Specimens could be readily stored in a desired environment for quantitative determination of long-term adhesion, which probably has greater clinical significance.

Testing OF BOND STRENGTH.-Tensile strengths of adhesive bonds were determined on a universal testing instrument using a crosshead speed of $0.05 \mathrm{~cm} /$ minute.

The conditioned specimens were placed in a jig held in the upper grip of the testing instrument, and the holder was engaged by an adapter rigidly held by the lower grip of the testing instrument (Fig 3).

Treatment of DaTA.- All bond strength means with their associated standard deviations, standard errors, and coefficients of variation were based on a sample size of nine unless otherwise noted. Zero adhesion specimens were included in calculations of mean bond strengths.

Differences between two means were tested for significance at the .05 level using a two-sided $t$ test. ${ }^{11}$

Multiple comparisons were performed on the five means for each test substrate using Duncan's new multiple range test ${ }^{11}$ when a one way classification analysis of variance indicated rejection of the hypothesis that the five means were equal at the .05 level of significance.

\section{Results}

Fluorapatate as a model substrate.Table 2 gives all data for a sample of 12 specimens of resin 4 tested against fluorapatite single crystals. Cohesive failure of several fluorapatite single crystals revealed that the cohesive strength of the fluorapatite single crystal was not always greater than the cohesive strength of the dental filling resin bonded to it.

TEST RELIABILITY.-The best measure of the reliability of the test method was felt to be the coefficients of variation for resinhigh energy metal substrate combinations: $C V=\frac{S}{\bar{x}} \cdot 100$, where $C V=$ coefficient of variation (expressed as \%), $S=$ standard deviation, and $\bar{x}=$ mean bond strength.

A small standard deviation relative to the mean bond strength results in a small coefficient of variation and reflects greater reliability.

Table 3 gives bond strength data for the five test resins against an aluminum substrate. These specimens were aged 22 to 26 hours in air at $37 \mathrm{C}$ to minimize the effect of moisture on the adhesive interface. Except for resin 5, which was dimensionally unstable in the desiccating atmosphere of the conditioning oven, the average coefficient of variation was $19.9 \%$. Any two means not covered by the same vertical line are significantly different at the .05 level.

TABLE 2

ADHESION TO FLUORAPATITE

RESIN 4 TO 100 PLANE*

\begin{tabular}{|c|c|c|c|c|c|c|c|c|c|c|c|c|}
\hline Specimen & $\bar{A}$ & $\mathbf{B}$ & $\mathrm{Ci}$ & $E$ & $\mathrm{~F} *$ & $G$ & $\mathrm{H}_{\dagger}$ & $I$ & $\mathrm{~J}$ & $\mathrm{~L}^{\dagger}$ & $\mathbf{M}$ & $N$ \\
\hline $\begin{array}{l}\text { Fx stress } \\
\mathrm{kg} / \mathrm{sq} \mathrm{cm}\end{array}$ & 57.9 & 72.1 & 68.1 & 75.6 & 0.0 & 64.0 & 55.9 & 70.1 & 57.9 & 94.0 & 71.1 & 48.2 \\
\hline
\end{tabular}

TABLE 3

AdHesion to Aluminum*

\begin{tabular}{lrrrr}
\hline Resin & $\bar{x}(\mathrm{~kg} / \mathrm{sq} \mathrm{cm})$ & $C V(\%)$ & $S$ & $S_{\bar{x}}$ \\
\hline 2 & 175.1 & 18.6 & 32.6 & 10.9 \\
4 & 98.6 & 17.1 & 16.9 & 6.6 \\
3 & 59.0 & 19.7 & 11.6 & 3.9 \\
1 & 52.5 & 24.2 & 12.7 & 4.2 \\
5 & 6.9 & 85.5 & 5.9 & 1.9 \\
\hline * & $\mathrm{F}^{\circ} .95(4,40)=2.61<139.1(p<.01)$ & &
\end{tabular}


SURFACE TREATMENT OF DENTAL SUbSTRates.-Citric Acid.-The decided improvement in adhesion to enamel after a citric acid etch is seen in Table 4. Except for resin 5, adhesion was improved, on average, over $200 \%$.

$\mathrm{MgCl}_{2}$ Treatment.-When enamel surfaces were rinsed with distilled water and air dried after a 20 minute immersion in $2 \mathrm{M} \mathrm{MgCl}$, two of six specimens survived unmolding, conditioning, and clamping into the testing jig to give measurable adhesion values of $2.0 \mathrm{~kg} / \mathrm{sq} \mathrm{cm}$. When $\mathrm{MgCl}_{2}$ is used in this manner, it inhibits adhesion when compared to a distilled water rinse.

APplication of tHE TEST METHOD.Bond strength data for the five test resins measured against bovine enamel and dentin are given in Table 4.

In each instance when the data were subjected to analysis of variance procedures to test the equivalence of the mean bond strengths, a critical $\mathrm{F}_{95}^{\circ}$ indicated rejection of the hypothesis that the mean bond strengths were equal.

The test discriminated among the bonding abilities of the five test resins to unetched wet ground bovine enamel by dividing the means into three ranks $(2>5>4,1,3)$ (Table 4). Discrimination into three ranks occurred also for citric acid etched bovine enamel $(4,2,3>1>5)$.

The test resins bonded much less strongly with bovine dentin, both treated and untreated, than with bovine enamel. Discrimination for unetched bovine dentin was into three ranks $(5>2>1,3,4)$. Etching improved adhesion to bovine dentin slightly, except for resin 5, though this substratesurface treatment combination resulted in reduced test sensitivity with discrimination into two ranks $(2>5,1,3)$.

\section{Discussion}

RESIN THICKNESS.-In the tests formulated by Bowen, ${ }^{\overline{5}}$ and Swartz and Phillips, ${ }^{4}$ resin thickness was measured but not controlled, so that the viscosity of the test resins at the time of specimen preparation, by governing resin thickness, exerted greater effects on mean bond strengths than differences in the inherent bonding abilities of the resins.

Of the two resin thicknesses examined, the $1 \mathrm{~mm}$ thickness was retained because it resulted in a greater mean bond strength with a slightly smaller coefficient of variation.

Fluorapatite as a MODEl substrate.When measuring adhesion of resin 4 to fluorapatite it was noted that specimens failed either by cohesive failure of the resin or of the fluorapatite single crystals. This indicated that an overlap exists in the distributions of the cohesive strengths of the resin and fluorapatite and that short term bond strengths of at least one resin with the

TABLE 4

ADDHESION TO BOVINE INCISORS

ENAMEL

\begin{tabular}{|c|c|c|c|c|c|c|c|c|c|}
\hline \multicolumn{5}{|c|}{ Unetched* } & \multicolumn{5}{|c|}{ Etched $\uparrow$} \\
\hline Resin & $\bar{x}(\mathrm{~kg} / \mathrm{sq} \mathrm{cm})$ & $C V(\%)$ & $S$ & $s_{\bar{x}}$ & Resin & $\bar{x}(\mathrm{~kg} / \mathrm{sq} \mathrm{cm})$ & $C V(\%)$ & $S$ & $s_{\bar{x}}$ \\
\hline 2 & 66.1 & 18.9 & 12.5 & 4.2 & 4 & 94.7 & 40.7 & 38.5 & 12.8 \\
\hline 5 & 35.0 & 21.4 & 7.5 & 2.5 & 2 & 85.2 & 20.1 & 17.1 & 5.7 \\
\hline 4 & 12.5 & 64.8 & 8.1 & 2.7 & 3 & 81.8 & 19.1 & 15.6 & 5.2 \\
\hline 1 & 11.0 & 61.8 & 6.8 & 2.3 & 1 & 59.0 & 28.8 & 17.0 & 5.7 \\
\hline 3 & 8.1 & 44.4 & 3.6 & 1.2 & 5 & 27.2 & 33.5 & 9.1 & 3.0 \\
\hline \multicolumn{10}{|c|}{ DENTIN } \\
\hline \multicolumn{5}{|c|}{ Unetched: } & \multicolumn{5}{|c|}{ Etcheds } \\
\hline 5 & 21.5 & 16.5 & 3.6 & 1.2 & 2 & 13.5 & 111.1 & 15.0 & 5.0 \\
\hline 2 & 6.0 & 48.3 & 2.9 & 0.9 & 4 & 8.6 & 123.2 & 10.6 & 5.0 \\
\hline 1 & 0.0 & $\ldots$ & $\ldots$ & $\ldots$ & 5 & 2.1 & 343.0 & 7.2 & 2.4 \\
\hline 3 & 0.0 & $\ldots$ & $\cdots$ & $\cdots$ & 1 & 0.0 & $\cdots$ & $\cdots$ & $\ldots$ \\
\hline 4 & 0.0 & $\ldots$ & $\ldots$ & $\ldots$ & 3 & 0.0 & . & $\ldots$ & $\ldots$ \\
\hline
\end{tabular}


inorganic fraction of enamel and dentin may be near the limiting value imposed by the substrate.

Previously reported evidence of water degradation of the bond interface ${ }^{3,13}$ was supported by the predominantly cohesive resin failure of resin 4 -etched enamel specimens where the outer portion of the interface failed adhesively, leaving a moisture altered film on the enamel surface.

Because of the high short-term bond strengths measured for some resins, and evidence of degradation by water of the adhesive interface, the most fruitful approzch to clinical adhesion may be found in a modification of the cut tooth surface, which promotes stability of the initial adhesive bond by preventing moisture from reaching the tooth-resin interface.

TEST RELIABILITY.- The result of testing a sample of size $n$ is best expressed as a sample mean $(\bar{x})$ along with an estimate of the variability of the universe from which the sample was drawn, expressed as the standard deviation $(S)$.

In almost every sampling operation, some variability is present and must be considered when making statements about differences in sample means. In any given situation, reductions in sample variability allow smaller differences between means to be declared significant.

When all other recognized sources of sample variability had been reduced, the use of a relatively invariant aluminum substrate allowed an evaluation of the test method without contributions to variability from less homogeneous biologic substrates.

A small coefficient of variation for a resinaluminum combination implied that the larger coefficients of variation seen in resintooth bonds were due to the inherent variability of the biologic substrates used rather than to the test method itself.

The degree of reliability reflected by an average coefficient of variation of $19.9 \%$ (excluding resin 5) proved satisfactory in statistically discriminating among the test resins.

APPLICATION OF THE TEST METHOD.-The test method was used to differentiate between the bonding abilities of five test resins to two dental substrates with and without surface treatments. Because of the variability associated with each sample mean, a statistical method for multiple comparisons was used so that differences in bonding abilities declared statistically significant could have occurred by chance less than 1 time in 20 .

Although the underlying assumptions of homoscedasticity and normality were not met in every test involving analysis of variance, balanced design and the nature of analysis of variance adequately support the validity of the test results.

Bovine enamel.-Bonding abilities of the five test resins against unetched bovine enamel were separated into three ranks $(2>5>4,1,3)$. After a citric acid etch of the enamel substrate, the separation of bonding abilities was again into three ranks $(4,2,3>1>5)$ although the rank order changed and mean bond strengths (excluding resin 5 , which apparently was adversely affected by the residue of citric acid on the substrate surface or the unavailability of active sites for adhesion after the etch) increased on average over $200 \%$.

The increase in microroughness resulting from the etching almost certainly increases the real area of the enamel substrate within the perimeter of the die which is available for bonding. Increasing the microroughness of the substrate also serves to decrease the apparent contact angle between the resin and the substrate, enhancing wetting with a resultant improvement in adhesion. ${ }^{12}$

Bovine dentin.-Except for resin 5 (carboxylate), bonding to untreated dentin was poor (resin 2), or not measurable (resins 1,3 , and 4 ). The test divided the bonding abilities into 3 ranks $(5>2>1,3,4)$. After the citric acid etch, three resins retained measurable bond strengths after conditioning in tap water, although the bonding ability of resin 5 was again adversely affected by the etch. The test divided the resins into two ranks $(2>5,1,3)$ of different bonding abilities.

The nature of the substrate controls, to a considerable extent, the ability of the test to indicate statistically significant differences in bonding abilities. It is extremely doubtful, however, that any clinically significant differences in adhesion would be declared nonsignificant for any of the substrates used.

\section{Summary}

A test method intended to measure the bond strengths of filling resin-dental substrate combinations under tensile loading has been evaluated and modified so that it is 
capable of statistically ranking the bonding abilities of commercially available dental resins. The test method is simple and inexpensive with demonstrated reliability. It should fill a need that currently exists for a test method to evaluate adhesive dental resins.

Dental substrates that served as model adherents were bovine enamel and bovine dentin. The sensitivity of the test proved adequate in discriminating among the bonding abilities of the five typical commercial resins to both substrates when they had been freshly surfaced and also when they had been etched with citric acid. Adhesion to enamel increased, on the average, over $200 \%$ after a citric acid etch. Adhesion to freshly surfaced dentin, which was minimal or nonexistent except for the carbohydrate cement, increased slightly after a citric acid etch.

The rank order of bond strengths was different for each substrate and was further altered by etching the surface of each substrate so that no single resin performed best under all conditions.

\section{References}

1. Epoxylite Corporation: Epoxylite Corporation Research Report RR-66-131, South E1 Monte, California.

2. UY, K.C., and Chang, R.: "An Approach to the Study of the Mechanisms of Adhesion in Teeth," in Second Workshop, Adhesive Restorative Dental Materials, $\mathrm{PH}$ Publication No. 1494, 1965, pp 103-133.

3. Patrick, R.L.; Kaplan, C.M.; and Beaver,
E.R.: Improved Dental Restorative Systems, $J$ Dent Res 47:12-20, 1968.

4. Swartz, M.L., and PhILlips, R.W.: A Method of Measuring the Adhesive Characteristics of Dental Cement, JADA 50:172. $177,1955$.

5. BowEN, R.L.: Adhesive Bonding of Various Materials to Hard Tooth Tissues: I. Method of Determining Bond Strength, $J$ Dent Res 44:690-695, 1965 .

6. Galitgan, J.D.; Schwartz, A.M.; and MinoR, F.W.: Adhesive Polyurethane Liners for Anterior Restorations, J Dent Res 47:629-632, 1968.

7. RoYdhouse, R.H., and RAMBoseK, G.M.: Pinhole Test for Adhesion, $J$ Dent Res 48: 1087-1093, 1968.

8. EICK, J.D.: Minutes of the May 2, 1967 Meeting of the Subcommittee on Standard Test Methods for Direct Filling Resins, Dental Materials Group, Chicago, American Dental Association, May 24, 1967.

9. SPIEGEL, M.R.: Statistics, New York: Schaum, 1961, p 157.

10. DziewiatkowSKI, D.D.: Personal communication.

11. Steel, R.G., and Torrie, J.H.: Principles and Procedures of Statistics, New York: McGraw-Hill, 1960, pp 67-87, 101-109.

12. ZismaN, W.A.: "Constitutional Effects on Adhesive and Abhesion," in Proceedings from the Adhesive Restorative Dental Materials Workshop, Spencer, Ind: Owen Litho Service, 1961, pp 103-136.

13. Rose, E.E.; LAL, J.; WilliaMs, N.B.; and FalCETTI, J.P.: "The Screening of Materials for Adhesion to Human Tooth Structure," in Proceedings from the Adhesive Restorative Dental Materials Workshop, Spencer, Ind: Owen Litho Service, 1961, pp 160-170. 